\title{
The G Protein-Coupled Receptor Kinase 4 Gene Modulates Stress-Induced Sodium Excretion in Black Normotensive Adolescents
}

\author{
HAIDONG ZHU, YANHUI LU, XIAOLING WANG, HAROLD SNIEDER, FRANK A. TREIBER, GREGORY A. HARSHFIELD, \\ AND YANBIN DONG
}

Department of Pediatrics [H.Z., Y.L., X.W., H.S., F.A.T., G.A.H., Y.D.], Georgia Prevention Institute, Medical College of Georgia, Augusta, GA 30912; Twin Research \& Genetic Epidemiology Unit [H.S.], St Thomas' Hospital, London, SE1 7EH, United Kingdom

\begin{abstract}
Approximately $20-40 \%$ of adolescents have shown a reduction of urinary sodium excretion $\left(\mathrm{U}_{\mathrm{Na}} \mathrm{V}\right)$ in response to blood pressure (BP) increase during behavioral stress. $G$ protein-coupled receptor kinase 4 (GRK4) mediates the pressure and natriuresis relation. The present study investigated the impact of GRK4 genetic variants on $\mathrm{U}_{\mathrm{Na}} \mathrm{V}$ under stress. A total of 664 normotensive adolescents including whites and blacks (17.6 \pm 3.3 yrs, $43.4 \%$ blacks $)$ were recruited. Participants were subjected to a stress-protocol including three 10-min tasks (a social competence interview, a virtual reality car driving simulation test, and a video game challenge), concluded by a urine collection. Three functional polymorphisms including R65L, A142V and A486V were genotyped. Given blacks compared with whites had significantly higher systolic BP (SBP) levels during rest $(p<0.001)$ and stress $(p \leq 0.001)$, there was no statistical difference in $\mathrm{U}_{\mathrm{Na}} \mathrm{V}$ in response to stress between the two ethnic groups. In blacks, compared with R65R homozygotes, individuals with R65L or L65L genotype had significantly lower levels of stress-induced $\mathrm{U}_{\mathrm{Na}} \mathrm{V}(8.42 \pm 0.63$ versus $9.85 \pm 0.37 \mathrm{mEq} / \mathrm{h}, p=$ 0.01). In summary, BP elevation seems uncoupled with $\mathrm{U}_{\mathrm{Na}} \mathrm{V}$ increase during behavioral stress in black adolescents. The $65 \mathrm{~L}$ allele of the GRK4 gene is associated with stress-induced $\mathrm{U}_{\mathrm{Na}} \mathrm{V}$ reduction, suggesting impaired sodium handling in affected black youth. (Pediatr Res 60: 440-442, 2006)
\end{abstract}

$\mathrm{E}$ ssential hypertension is determined by gene and environment interactions, and has its origin in childhood. Blood pressure (BP) increase during a sustained period of behavioral stress is typically accompanied by a compensatory increase in urinary sodium excretion $\left(\mathrm{U}_{\mathrm{Na}} \mathrm{V}\right)(1,2)$. Our previous data show that an inadequate compensatory increase in $\mathrm{U}_{\mathrm{Na}} \mathrm{V}$ in response to stress occurs in $20-40 \%$ of adolescents aged 15-19 y (Harshfield et al. Annual Meeting of Society of Behavioral Medicine, April 13-16, 2005, Boston), which may predict the development of hypertension $(1,2)$. In particular, we have recently demonstrated that $\mathrm{U}_{\mathrm{Na}} \mathrm{V}$ in response to stress is a heritable phenotype in a multi-ethnic cohort of adolescents

Received November 28, 2005; accepted May 31, 2006.

Correspondence: Yanbin Dong, M.D., Ph.D., Georgia Prevention Institute, Department of Pediatrics, Medical College of Georgia, $112015^{\text {th }}$ Street, HS-1640, Augusta, GA 30912-3715; Email: ydong@ mcg.edu

This study was supported by grants from National Heart, Lung, and Blood Institute (HL076723, RO1HL56622 and HL69999) and the American Heart Association $(0430078 \mathrm{~N}, 0435146 \mathrm{~N}$ and 0425447B).

DOI: 10.1203/01.pdr.0000238250.64591.44
(Ge et al., Annual meeting of the American Society of Human Genetics, October 25-29, 2005, Salt Lake City). However, no candidate gene association study has been performed to date.

Dopamine enhances renal sodium excretion, diuresis and natriuresis via dopamine receptors D (DRD) in the renal proximal tubules (3-5). G protein-coupled receptor kinase 4 (GRK4) regulates DRD1 phosphorylation, desensitization and internalization $(6,7)$. Although functional single nucleotide polymorphisms (SNPs) of the GRK4 gene have been associated with hypertension in adult populations (8-11), the impact of these variants on sodium homeostasis in humans remains unknown. Thus we conducted association analyses of the GRK4 polymorphisms in relation to stress-induced $\mathrm{U}_{\mathrm{Na}} \mathrm{V}$ in a sample of young normotensive white and black twins.

\section{METHODS}

Study population. A total of 664 normotensive twin subjects including whites and blacks ( $43.4 \%$ blacks) were available for this study. There were 330 monozygotic (MZ) and 334 dizygotic (DZ) twin individuals. Recruitment of twin pairs and zygosity determination has been previously described in the Georgia Cardiovascular Twin Study (12-14). The Institutional Review Board at the Medical College of Georgia approved the study. Informed consent was obtained from subjects or from parents if subjects were under $18 \mathrm{y}$.

Measurements. Overnight urine was collected for baseline evaluation of $\mathrm{U}_{\mathrm{Na}} \mathrm{V}$. Upon arrival the subjects voided and rested in a supine position for 15 min. Participants were then subjected to a two-hour experimental protocol consisting of an echocardiographic evaluation (15) and three 10-min stress tasks, a social competence interview (16), a virtual reality car driving simulation test (17), and a video game challenge (18) interspersed with recovery periods, and concluded by a urine collection. $\mathrm{U}_{\mathrm{Na}} \mathrm{V}$ was denoted as an excretion rate, i.e., excretion of urinary sodium per unit of time. Systolic BP (SBP) and diastolic BP (DBP) were recorded every other minute during the three stress tasks and averaged to represent stress BP levels (1). SBP and DBP reactivity were calculated as percentage change on SBP and DBP, respectively.

Genotyping. The three functional SNPs, R65L, A142V and A486V, were detected by polymerase chain reaction with restriction fragment length polymorphism analysis. Information about primers and digestion enzymes are available from the corresponding author.

Statistical analyses. All regular association analyses were performed using Generalized Estimating Equations, which take the non-independency of twin data into account and yields unbiased $p$-values $(19,20)$. We first modeled the effects of age, ethnicity, gender and body mass index (BMI) on $\mathrm{U}_{\mathrm{Na}} \mathrm{V}$ variation. After

Abbreviations: BP, blood pressure; DBP, diastolic blood pressure; GRK4, G protein-coupled receptor kinase 4; HTR, haplotype trend regression; LD, linkage disequilibrium; $\mathbf{S B P}$, systolic blood pressure; $\mathbf{U}_{\mathbf{N a}} \mathbf{V}$, urinary sodium excretion 
arriving at the most parsimonious full environmental model including only significant terms, polymorphisms or haplotypes were then added to test for main effects and interactions. Simultaneously modeling gender and ethnicity as factors in our model is more powerful than subgroup analyses, and it also allows us to statistically test for gender and ethnic specific effects of the polymorphisms and haplotypes. Overnight sodium excretion rate was put into the model as a covariate to adjust for the potential effects of different sodium intake. The haplotype trend regression (HTR) approach was used to test for associations of statistically inferred haplotypes with $\mathrm{U}_{\mathrm{Na}} \mathrm{V}$ levels (21-23).

Hardy-Weinberg equilibrium and ethnic differences in allele and genotype frequencies were tested by a $\chi^{2}$ test in subjects including only one of each twin pair chosen randomly to prevent inflated significance. $\mathrm{U}_{\mathrm{Na}} \mathrm{V}$ during stress was log-transformed to obtain better approximations of the normal distribution. Single locus association analyses and HTR were performed with STATA 8 (StataCorp, College Station, Texas).

\section{RESULTS}

General characteristics of 664 study subjects and descriptive statistics by ethnicity and gender are shown in Table 1 . Age and height were similar in the two ethnic groups. We found significant interactions between ethnicity and gender for weight $(p=0.002)$ and BMI $(p=0.004)$. In females, weight and BMI were greater in blacks than in whites. Compared with whites, blacks had significantly higher SBP/DBP levels at rest $(p<0.001)$ and stress $(p \leq 0.001)$ as well as higher level of overnight $\mathrm{U}_{\mathrm{Na}} \mathrm{V}(p=0.025)$. SBP and DBP reactivity were greater in whites than in blacks, respectively $(p<0.001)$. Of note, there was no statistical difference in $\mathrm{U}_{\mathrm{Na}} \mathrm{V}$ during stress between the two ethnic groups. In comparison with females, males had higher levels of SBP $(p<0.001)$ at rest and under stress. Similarly, overnight and stress levels of $\mathrm{U}_{\mathrm{Na}} \mathrm{V}$ were higher in males than in females ( $p \leq 0.005)$.

Table 2 shows the allele and genotype distributions in whites and blacks. Allele and genotype frequencies differed significantly between whites and blacks. Strong linkage disequilibrium (LD) was observed between all three SNPs, but none of the SNP pairs were in complete LD $\left(\mathrm{D}^{\prime}=\right.$ $0.515 \sim 0.830$ ). None of the three loci deviated from Hardy Weinberg equilibrium in whites or blacks (all ps $>0.05$ ).

In single locus association analyses, under the assumption of a dominant effect of the $65 \mathrm{~L}$ allele, a significant interaction was uncovered between ethnicity and the R65L polymorphism for $\mathrm{U}_{\mathrm{Na}} \mathrm{V}$ in response to stress $(p=0.01)$. As shown in Fig. 1, only in blacks, carriers of the $65 \mathrm{~L}$ allele compared with R65R homozygotes had a significantly lower level of $\mathrm{U}_{\mathrm{Na}} \mathrm{V}$ during stress $(8.42 \pm 0.63$ versus $9.85 \pm 0.37 \mathrm{mEq} / \mathrm{h}, p=0.01)$. Further, the R65L polymorphism explained about $2 \%$ of the total variance in stress $\mathrm{U}_{\mathrm{Na}} \mathrm{V}$ in the blacks. Adjustment for overnight $\mathrm{U}_{\mathrm{Na}} \mathrm{V}$, weight, BMI, gender, and SBP /DBP during stress did not change the significance $(p<0.05)$. No significant main effects of haplotypes were observed on overnight or stress $\mathrm{U}_{\mathrm{Na}} \mathrm{V}$ (results not shown).

\section{DISCUSSION}

The observation that blacks had significantly higher SBP/DBP at rest and during stress is consistent with our previous findings and those in the literature. A higher night time $\mathrm{U}_{\mathrm{Na}} \mathrm{V}$ in blacks compared with whites may be due to the higher dietary salt intake. There was no difference in $\mathrm{U}_{\mathrm{Na}} \mathrm{V}$ in response to stress between the two ethnic groups, although stress levels of SBP and DBP were higher in blacks than whites. These suggest an uncoupling between pressure and natriuresis during stress in blacks. Despite higher SBP/DBP at baseline, blacks exhibited lower SBP/DBP reactivity (\%) compared with whites, suggesting ethnicity-dependent BP regulatory mechanisms (24).

Of interest, in blacks, even after adjustment for SBP and DBP during stress, and overnight $\mathrm{U}_{\mathrm{Na}} \mathrm{V}$, the $65 \mathrm{~L}$ allele was significantly associated with a reduction of $\mathrm{U}_{\mathrm{Na}} \mathrm{V}$ in response to stress. As such, sodium handling in the kidney might be impaired in black adolescents with R65L or L65L genotype. The genetic effects were independent from the effects of overnight sodium excretion, a proxy of sodium intake. Of note, overnight urine might not be an ideal specimen for baseline $\mathrm{U}_{\mathrm{Na}} \mathrm{V}$. However, we also collected a urine sample before the stress protocol and found that this prestress $\mathrm{U}_{\mathrm{Na}} \mathrm{V}$ was not significantly different from the overnight $\mathrm{U}_{\mathrm{Na}} \mathrm{V}$ (data not shown). On the other hand, overnight $\mathrm{U}_{\mathrm{Na}} \mathrm{V}$ collected over a longer period of time may provide a more stable measurement. Our finding suggests the need for further research of the influence of the GRK4 gene variation on renal natriuresis in subjects with a sodium-controlled diet.

Table 1. General characteristics of study subjects

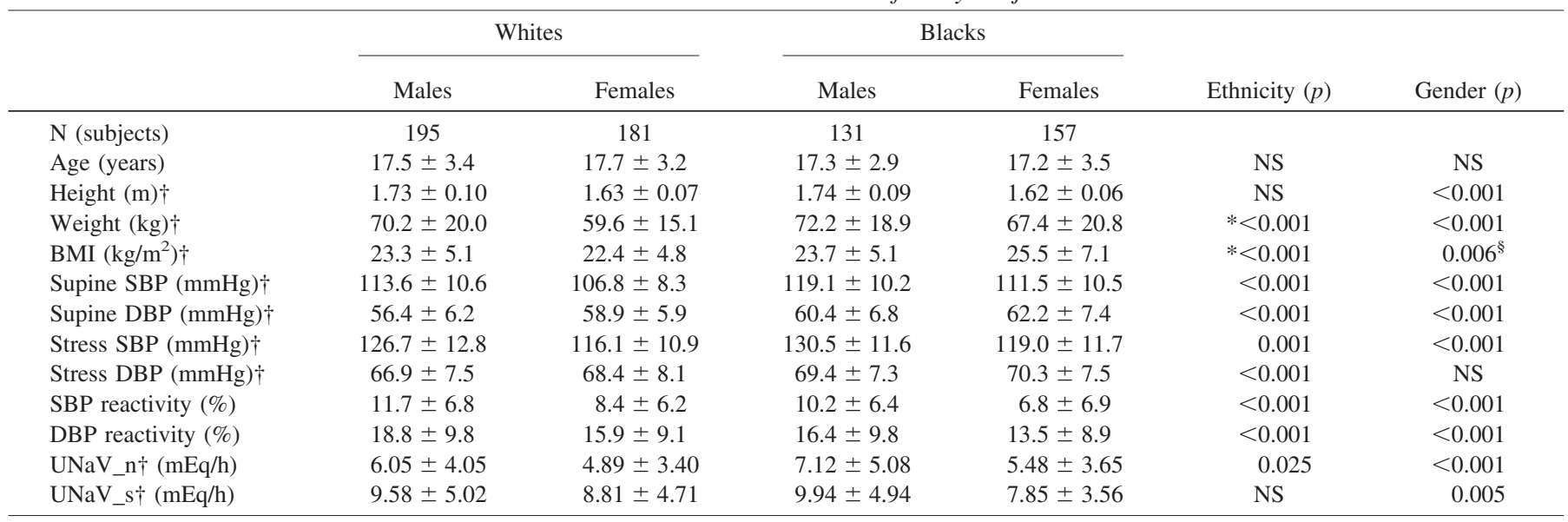

Mean \pm SD is shown unless indicated otherwise.

NS, not significant; SBP, systolic BP; DBP, diastolic BP; $\mathrm{U}_{\mathrm{Na}} \mathrm{V} \_n, \mathrm{U}_{\mathrm{Na}} \mathrm{V}$ overnight; $\mathrm{U}_{\mathrm{Na}} \mathrm{V} \_\mathrm{s}, \mathrm{U}_{\mathrm{Na}} \mathrm{V}$ during stress.

* Significant only in females; $\S$ significant only in blacks.

$\dagger$ Age was adjusted for the evaluation of ethnicity and gender effects. 
Table 2. Genotype and Allele Frequencies of the three SNPs in whites and blacks

\begin{tabular}{|c|c|c|c|c|c|c|c|c|}
\hline SNPs & Ethnicity & $\mathrm{N}$ & Genotype 11 & Genotype 12 & Genotype 22 & $P^{*}$ & Allele Freq. & $P^{*}$ \\
\hline \multirow[t]{2}{*}{ R65L } & Whites & 271 & 117 & 116 & 38 & $<0.001$ & $0.653 / 0.347$ & $<0.001$ \\
\hline & Blacks & 216 & 49 & 121 & 46 & & $0.507 / 0.493$ & \\
\hline \multirow[t]{2}{*}{ A142V } & Whites & 274 & 120 & 121 & 33 & $<0.001$ & $0.659 / 0.341$ & $<0.001$ \\
\hline & Blacks & 220 & 34 & 110 & 76 & & $0.405 / 0.595$ & \\
\hline \multirow[t]{2}{*}{ A486V } & Whites & 274 & 107 & 132 & 35 & $<0.001$ & $0.631 / 0.369$ & $<0.001$ \\
\hline & Blacks & 219 & 176 & 40 & 3 & & $0.895 / 0.105$ & \\
\hline
\end{tabular}

$\mathrm{N}$ is the number of subjects including one of each MZ twin pair and both DZ twins of a pair; * p-values are based on tests in one twin of each pair

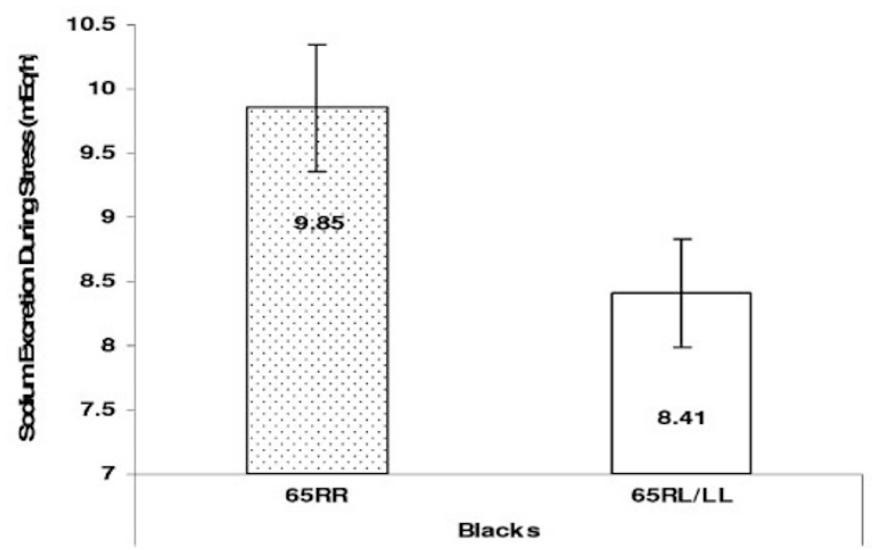

Figure 1. The effect of the $65 \mathrm{~L}$ allele on $\mathrm{U}_{\mathrm{Na}} \mathrm{V}$ during stress in 216 blacks. $p=0.01$.

In Chinese hamster ovary cells in vitro, the $65 \mathrm{~L}$ allele was involved in a decrease in cAMP production as well as an increase in DRD1 phosphorylation, which may subsequently inhibit the diuretic and natriuretic effects of renal dopamine $(6,7)$. Further, it was shown that this allele tracked with BP elevation in adult hypertensives (11). Given the high frequency of the $65 \mathrm{~L}$ allele in blacks $(49 \%)$, it is likely to have an impact on the development of hypertension in blacks at the population level. A longitudinal study is required to reveal the effects of the GRK4 R65L polymorphism on renal natriuresis and BP development in these black young individuals. It is unclear why the effect of the R65L polymorphism on sodium excretion was not observed in whites. Our recent data indicate that impaired SIPN is approximately twice as prevalent in black as in white youth (40\% versus 20\%) (Harshfield et al., Annual Meeting of Society of Behavioral Medicine, April 13-16, 2005, Boston). The genetic and environmental determinants of salt sensitivity and pressure natriuresis are speculated to be race-related (25).

A genetic predisposition to retain sodium is hypothesized as one possible reason for salt sensitive hypertension, especially in the black population. This present study has taken this hypothesis a step further by examining the interaction between genes and environmental stress in this process. $\mathrm{U}_{\mathrm{Na}} \mathrm{V}$ in response to stress is a new phenotype of sodium homeostasis and $\mathrm{BP}$, which can be used in candidate gene association studies. Increased understanding of the contribution of GRK4 will further elucidate the importance of the dopaminergic pathway in BP regulation. Screening GRK4 gene variants might identify a subset of individuals that are particularly susceptible as early as possible, so preventative strategies, e.g., low-salt diets and stress management training can be taken.

\section{REFERENCES}

1. Harshfield GA, Treiber FA, Davis H, Kapuku GK 2002 Impaired stress-induced pressure natriuresis is related to left ventricle structure in blacks. Hypertension 39:844-847

2. Harshfield GA, Wilson ME, Hanevold C, Kapuku GK, Mackey L, Gillis D, Treiber FA 2002 Impaired stress-induced pressure natriuresis increases cardiovascularload in African American youths. Am J Hypertens 15:903-906

3. Jose PA, Eisner GM, Felder RA 2002 Role of dopamine receptors in the kidney in the regulation of blood pressure. Curr Opin Nephrol Hypertens 11:87-92

4. Jose PA, Eisner GM, Felder RA 2003 Dopamine and the kidney: a role in hypertension? Curr Opin Nephrol Hypertens 12:189-194

5. Hussain T, Lokhandwala MF 1998 Renal dopamine receptor function in hypertension. Hypertension 32:187-197

6. Felder RA, Sanada H, Xu J, Yu PY, Wang Z, Watanabe H, Asico LD, Wang W, Zheng S, Yamaguchi I, Williams SM, Gainer J, Brown NJ, Hazen-Martin D, Wong LJ, Robillard JE, Carey RM, Eisner GM, Jose PA 2002 G protein-coupled receptor kinase 4 gene variants in human essential hypertension. Proc Natl Acad Sci USA 99:3872-3877

7. Zeng C, Sanada H, Watanabe H, Eisner GM, Felder RA, Jose PA 2004 Functional genomics of the dopaminergic system in hypertension. Physiol Genomics 19:233-246

8. Casari G, Barlassina C, Cusi D, Zagato L, Muirhead R, Righetti M, Nembri P, Amar K, Gatti M, Macciardi F 1995 Association of the alpha-adducin locus with essential hypertension. Hypertension 25:320-326

9. Williams SM, Addy JH, Phillips JA3rd, Dai M, Kpodonu J, Afful J, Jackson H, Joseph K, Eason F, Murray MM, Epperson P, Aduonum A, Wong LJ, Jose PA, Felder RA 2000 Combinations of variations in multiple genes are associated with hypertension. Hypertension 36:2-6

10. Bengra C, Mifflin TE, Khripin Y, Manunta P, Williams SM, Jose PA, Felder RA 2002 Genotyping of essential hypertension single-nucleotide polymorphisms by a homogeneous PCR method with universal energy transfer primers. Clin Chem 48:2131-2140

11. Speirs HJ, Katyk K, Kumar NN, Benjafield AV, Wang WY, Morris BJ 2004 Association of G-protein-coupled receptor kinase 4 haplotypes, but not HSD3B1 or PTP1B polymorphisms, with essential hypertension. J Hypertens 22:931-936

12. Snieder H, Treiber FA 2002 The Georgia Cardiovascular Twin Study. Twin Res 5:497-498

13. Jackson RW, Snieder H, Davis H, Treiber FA 2001 Determination of twin zygosity: A comparison of DNA with various questionnaire indices. Twin Res 4:12-18

14. Snieder H, Dong Y, Barbeau P, Harshfield GA, Dalageogou C, Zhu H, Carter N, Treiber FA 2002 beta2-adrenergic receptor gene and resting hemodynamics in European and African American youth. Am J Hypertens 15:973-979

15. Kapuku GK, Treiber FA, Davis HC, Harshfield GA, Cook BB, Mensah GA 1999 Hemodynamic function at rest, during acute stress, and in the field: predictors of cardiac structure and function 2 years later in youth. Hypertension 34:1026-1031

16. Ewart CK, Kolodner KB 1991 Social competence interview for assessing physiological reactivity in adolescents. Psychosom Med 53:289-304

17. Turner JR, Treiber FA, Davis H, Rectanwald J, Pipkin W, Strong WB 1997 Use of a virtual reality car driving stressor in cardiovascular reactivity research. Behav Res Methods Instrum Comput 29:386-389

18. Treiber FA, Musante L, Kapuku G, Davis C, Litaker M, Davis H 2001 Cardiovascular (CV) responsivity and recovery to acute stress and future CV functioning in youth with family histories of CV disease: a 4-year longitudinal study. Int J Psychophysiol 41:65-74

19. Tregouet DA, Ducimetiere P, Tiret L 1997 Testing association between candidategene markers and phenotype in related individuals, by use of estimating equations. Am J Hum Genet 61:189-199

20. Grainger DJ, Heathcote K, Chiano M, Snieder H, Kemp PR, Metcalfe JC, Carter ND, Spector TD 1999 Genetic control of the circulating concentration of transforming growth factor type beta1. Hum Mol Genet 8:93-97

21. Zaykin DV, Westfall PH, Young SS, Karnoub MA, Wagner MJ, Ehm MG 2002 Testing association of statistically inferred haplotypes with discrete and continuous traits in samples of unrelated individuals. Hum Hered 53:79-91

22. Dong Y, Zhu H, Wang X, Dalageorgou C, Carter N, Spector TD, Snieder H 2004 Obesity reveals an association between blood pressure and the G-protein beta3subunit gene: a study of female dizygotic twins. Pharmacogenetics 14:419-427

23. Zhu H, Wang X, Dong Y, Treiber FA, Snieder H 2005 Influence of the eNOS gene on development of blood pressure and left ventricular mass: longitudinal findings in multiethnic youth. Pharmacogenet Genomics 15:669-675

24. Treiber FA, Kamarck T, Schneiderman N, Sheffield D, Kapuku G, Taylor T 2003 Cardiovascular reactivity and development of preclinical and clinical disease states. Psychosom Med 65:46-62

25. Sagnella GA 2001 Why is plasma renin activity lower in populations of African origin? J Hum Hypertens 15:17-25 